\title{
\#Stayathome: Smart working for radiation oncologists during the corona pandemic
}

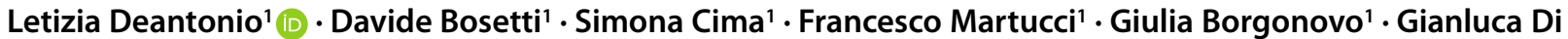 \\ Bella ${ }^{1}$. Gianfranco Angelo Pesce ${ }^{1}$ Mariacarla Valli' · Antonella Richetti ${ }^{1}$
}

Received: 28 May 2020 / Accepted: 24 August 2020 / Published online: 18 September 2020

(c) Springer-Verlag GmbH Germany, part of Springer Nature 2020

On 11 March 2020, the novel coronavirus (SARS-CoV-2) outbreak was declared a pandemic by the World Health Organization [1, 2]. In Switzerland, a total of 44,592 cases and 2,014 deaths were reported on 8 September 2020. On 25 February 2020, the first Swiss patient with COVID19 was diagnosed in southern Switzerland (canton Ticino). Since then, southern Switzerland has been one of the regions most affected by the pandemic [3].

In order to cope with the presence of COVID patients, hospital management reorganized departments to minimize the risk of transmission for patients and staff. In such a dramatic scenario, cancer patients are particularly frail and are at risk of severe events related to COVID-19. Radiation oncology departments faced two urgent requirements: (i) protect cancer patients and medical/paramedical staff from the risk of viral infection and (ii) guarantee radiation treatment that requires very specific skills and fixed time schedules [4-6].

The global response to this crisis started with the hashtag \#stayathome, to stress the importance of the first healthcare measure adopted to mitigate SARS-CoV-2 infection. Worldwide, the lockdown forced the implementation of remote and teleworking. The healthcare system had to face a great challenge, as the presence of medical and paramedical staff is a key component. However, several patient-related activities in particular treatment planning, reviewing files, multidisciplinary consultations, as well as research and quality assurance do not require physical presence at work, making so-called "smart working" feasible [7-9].

In our radiation oncology clinic at the Oncology Institute of Southern Switzerland, we reorganized the daily rou-

Dr. Letizia Deantonio, MD

letizia.deantonio@eoc.ch

1 Radiation Oncology Clinic, Oncology Institute of Southern Switzerland (IOSI), Bellinzona-Lugano, Via Gallino, 6500 Bellinzona, Switzerland tine following $\mathrm{WHO}$ and national statements. With properly implemented remote access to treatment planning workstations and medical records, radiation oncologists stayed at home 1-2 days per week in remote working. This allowed phone and skype consultations in order to reduce the number of onsite patient visits. This novel set-up allowed optimal social-distancing measures and staff protection, proved by the absence of cross infection.

In addition, the daily staff meeting was converted to a teleconference meeting in order to discuss (i) upcoming patients and radiotherapy strategy, (ii) implementing hypofractionation if clinically indicated $[6,10]$, and (iii) procedure update. Moreover, the new communication setting worked positive to share problems and the stressful situation in such a difficult period. Furthermore, the teleconference room system, which was already available for weekly multidisciplinary tumor board consultations, was broadly encouraged.

In the first phase of the pandemic, procedures of containment (e.g., social distancing) were essential to mitigate the spread of the virus and, at the time of writing, are still necessary for maintaining low the risk of infection.

The past months revealed that - with adequate technology support-remote working is feasible for radiation oncologist routine allowing both patient care and adequate precautions to reduce SARS-CoV-2 transmission and may be continued in the following months.

Conflict of interest L. Deantonio, D. Bosetti, S. Cima, F. Martucci, G. Borgonovo, G. Di Bella, G.A. Pesce, M. Valli and A. Richetti declare that they have no known competing interests.

\section{References}

1. https://coronavirus.jhu.edu/map.html. Accessed: 8 Sep 2020

2. Filippi AR, Russi E, Magrini SM et al (2020) Covid-19 outbreak in northern Italy: first practical indications for radiotherapy departments. Int J Radiat Oncol Biol Phys. https://doi.org/10.1016/j. ijrobp.2020.03.007

3. https://www.corona-data.ch/. Accessed: 8 Sep 2020 
4. Baumann M, Krause M, Overgaard J et al (2016) Radiation oncology in the era of precision medicine. Nat Rev Cancer 16:234-249

5. Meattini I, Franco P, Belgioia L et al (2020) Radiation therapy during the coronavirus disease 2019 (covid-19) pandemic in Italy: a view of the nation's young oncologists. ESMO Open. https://doi. org/10.1136/esmoopen-2020-000779

6. Guckenberger M, Belka C, Bezjak A et al (2020) Practice recommendations for lung cancer radiotherapy during the covid-19 pandemic: An ESTRO-ASTRO consensus statement. Radiother Oncol. https://doi.org/10.1016/j.radonc.2020.04.001

7. Slotman BJ, Ricardi U, Lievens Y (2020) Radiotherapy in a time of crisis, ESTRO Presidents's statement
8. Sack C, Sack H, Willich N, Popp W (2020) Evaluation of the time required for overhead tasks performed by physicians, medical physicists, and technicians in radiation oncology institutions The DEGRO-QUIRO study. Strahlenther Onkol 191:113-124

9. Achard V, Tsoutsou P, Zilli T (2020) Radiotherapy in the time of the Coronavirus pandemic: when less is better. Int $\mathrm{J}$ Radiat Oncol Biol Phys. https://doi.org/10.1016/j.ijrobp.2020.03.008

10. Thomson D, Palma D, Guckenberger M et al (2020) Practice recommendations for risk-adapted head and neck cancer radiotherapy during the covid-19 pandemic: An ASTRO-ESTRO consensus statement. Int J Radiat Oncol Biol Phys. https://doi.org/10.1016/j. ijrobp.2020.04.016 